\title{
Muskellunge Spawning Site Selection in Northern Wisconsin Lakes and a GIS-Based Predictive Habitat Model
}

\author{
Joel K. Nohner*¹ and James S. Diana \\ School of Natural Resources and Environment, University of Michigan, G128A Dana Building, \\ Ann Arbor, Michigan 48109, USA
}

\begin{abstract}
Spawning habitat degradation has been linked to declines in naturally reproducing Muskellunge Esox masquinongy populations, and managers require efficient methods to identify and protect these habitats. We collected spawning habitat data from 28 lakes in northern Wisconsin to determine Muskellunge spawning habitat selection and to create a GIS-based model for predicting the locations of spawning sites. Spawning site selection by Muskellunge may be more complex than previously thought. Muskellunge showed selection for spawning in habitats with a sheltered effective fetch and east-facing shorelines. The strongest selection was for habitats with a combination of moderate slope, small flats, and concave bathymetric curvature. Muskellunge selected against steeply sloping shorelines; very large areas of shallow flats; developed shorelines; herbaceous wetlands; and complex-leafed submersed aquatic vegetation. Lake trophic status appears to interact with other habit variables to determine spawning site selection; sites without submersed aquatic vegetation were more strongly selected in eutrophic lakes than in other lake types. A GIS model of spawning site selection was created using the machine learning program MaxEnt (Maximum Entropy Modeling). The model predicted that Muskellunge would spawn in areas with moderately sheltered effective fetches, moderate to small areas of shallow flats, away from outflowing streams, and (to a lesser extent) along shorelines facing east or west. The model was tested on novel lakes using area-under-thecurve (AUC) analysis, in which values ranged from 0.5 (predictions no better than random) to 1.0 (perfect assignment). The mean $\mathrm{AUC}_{\text {test }}$ value (i.e., the expectation of model performance for a novel lake) was 0.637 (SD = 0.12). When the model was used to designate the best $20 \%$ of available spawning habitat area for Muskellunge in each lake (based on the relative probability of spawning), that area contained $32 \%$ of the spawning sites. The model provides an efficient method for management agencies and conservation groups to use in designating spawning habitat for conservation and in communicating with the public through spawning habitat maps.
\end{abstract}

The Muskellunge Esox masquinongy is an ecologically and economically important species, acting as a top predator in aquatic ecosystems and driving multimillion-dollar fishing industries (Menz and Wilton 1983; Younk and Cook 1992; Bozek et al. 1999). However, the species has experienced declines in natural reproduction throughout its native range (Dombeck et al. 1986; Inskip 1986). Stocking has been attempted to counter some of these losses by supplementing or replacing natural reproduction. However, stocking is expensive (Margenau 1992), can spread or be affected by disease, and influences the genetic composition of individual fish stocks (Miller et al. 2009). In the face of increasing human populations and their effects on Muskellunge spawning habitat, the most cost-effective long-term approach may be to preserve natural reproduction. Therefore, managers must be able to accurately and efficiently identify Muskellunge spawning habitat.

Muskellunge have been described as typically spawning in shallow water $(<1.5 \mathrm{~m})$, although offshore locations as deep as $3.7 \mathrm{~m}$ have been reported (Scott and Crossman 1973;

\footnotetext{
*Corresponding author: jnohner@gmail.com

${ }^{1}$ Present address: Center for Systems Integration and Sustainability, Michigan State University, 115 Manly Miles Building, 1405 South Harrison Road, East Lansing, Michigan 48823, USA.

Received January 26, 2014; accepted October 7, 2014
} 
Dombeck et al. 1984; Pierce et al. 2007). Previous research has identified spawning in marshy areas near a variety of emergent vegetation or submersed aquatic vegetation (SAV; Dombeck et al. 1984; Farrell et al. 1996; Monfette et al. 1996; Younk et al. 1996; Farrell 2001), but spawning also occurs in areas without vegetation (Haas 1978). Large woody debris has also been linked with successful natural reproduction by Muskellunge (Dombeck et al. 1984; Zorn et al. 1998; Rust et al. 2002).

A number of studies have provided insight into Muskellunge spawning habitat requirements; however, the methodologies used often limit the generalization of results. Low Muskellunge densities and the substantial effort required to identify spawning sites have limited the sample size in many studies (Dombeck et al. 1984; Craig and Black 1986; Miller and Menzel 1986; Strand 1986; Werner et al. 1996; Murry and Farrell 2007; Pierce et al. 2007). Additionally, selecting known spawning areas as study sites has the potential to bias habitat characterizations (Craig and Black 1986). Methods that fail to statistically compare nursery or spawning habitat with available habitat can make conclusions about habitat usage but not about habitat selection (Craig and Black 1986; Strand 1986; Pierce et al. 2007). Finally, studies that focus on habitat characteristics contributing to natural reproduction at the whole-lake scale lack the resolution to determine habitat selection (Dombeck et al. 1986; Zorn et al. 1998; Rust et al. 2002).

Fisheries managers are increasingly utilizing spatial models to identify critical habitats for conservation and restoration. Although models for Muskellunge spawning habitat have been created, most are limited to whole-lake classifications for the presence of successful natural reproduction (Dombeck et al. 1986; Rust et al. 2002). Based upon a literature review, Farmer and Chow-Fraser (2004) created a conceptual model with parameters for three primary requirements of spawning habitat: temperature, dissolved oxygen (DO), and spatial separation of eggs at a level sufficient to minimize fungus. Crane et al. (2014) created a MaxEnt (Maximum Entropy Modeling; Phillips et al. 2006) model characterizing Muskellunge spawning habitat in the Niagara River, but that model may not be applicable to lake systems. No empirical model has been developed to predict the location of Muskellunge spawning in a given lake. Such information is vital to both managers and land owners who wish to protect critical habitat.

Geographical information systems data for land cover, bathymetry, and sometimes even aquatic vegetation are now available, enabling development of models that move beyond simple binary maps of presence/absence to continuous probability distributions mapping the relative likelihood of species presence. We used MaxEnt (Phillips et al. 2006) because it generally outperforms other modeling methods in predicting species distributions when only presence data are available (Elith et al. 2006; Hernandez et al. 2006). MaxEnt provides a simple user interface that allows end users (managers) to implement the model. Initially designed to map species distributions, MaxEnt has also been applied to mapping the habitat requirements of species during life history phases such as reproduction (Yost et al. 2008).

To investigate spawning habitat selection by Muskellunge, we compared the characteristics of a large number of observed spawning sites to the characteristics of available habitat in 28 northern Wisconsin lakes. The objectives of this study were to (1) identify habitats that Muskellunge select for spawning; (2) determine whether spawning site selection differs in relation to lake trophic status; and (3) use the MaxEnt program to create a GIS-based model for predicting the locations of spawning sites in novel lakes based on remotely sensed and available habitat data. Conventional statistics were used to analyze habitat selection across all variables and to produce readily interpreted selection coefficients. Conventional statistics complement the results of the "black box" MaxEnt modeling approach, which sacrifices some interpretability in exchange for improved modeling performance (Elith et al. 2006; Hernandez et al. 2006). Results from this study benefit fisheries and habitat management by identifying the characteristics of spawning habitat selected by Muskellunge and providing an efficient method for managers to delineate likely spawning habitat in lakes by using remotely measured or existing data sets.

\section{METHODS}

We investigated Muskellunge spawning habitat in 28 lakes located in the Northern Highlands Lake District of Wisconsin (Table 1). The lakes represented a wide diversity of lake types, ranging from oligotrophic to eutrophic and from small (50 ha) to large $(1,435 \mathrm{ha})$. To minimize the potential effects of stocking on site selection by Muskellunge, we chose lakes that supported naturally reproducing populations and that had not been stocked for at least 10 years prior to being surveyed.

Spawning site determination.-Spawning sites were identified using nighttime spotlighting surveys during the spawning period (after Zorn et al. 1998). The entire shallow-water area (depth $<1.5 \mathrm{~m}$ ) of each lake was surveyed. Due to the large size of spawning Muskellunge and the shallow water surveyed, detection probability was assumed to be equivalent across all surveyed habitats. Adult Muskellunge were defined as those fish with TLs greater than $0.6 \mathrm{~m}$ as determined by visual estimation. Locations of each adult Muskellunge were recorded as potential spawning sites by using a Trimble GeoXM GPS unit (Trimble Navigation Ltd., Sunnyvale, California). Although the spotlighting method precluded observations of fish potentially spawning in deeper water (Pierce et al. 2007), deepwater spawning sites are likely to be exceptions (Farrell 2001; Pierce et al. 2007).

Spotlighting surveys were completed from April 23 to May 9, 2007, and from May 5 to May 23, 2008, with most lakes being surveyed in one night. This minimized the number of 
TABLE 1. A summary of Wisconsin lakes used in this study, including counties, surface area, Carlson's trophic state index (TSI) value, Northern Pike presence, and whether substrate, emergent vegetation, and submersed aquatic vegetation data were collected in habitat surveys.

\begin{tabular}{|c|c|c|c|c|c|}
\hline Name & County & Surface area (ha) & TSI & Habitat survey & Northern Pike presence \\
\hline Amik & Vilas & 57 & 52 & & $\mathrm{X}$ \\
\hline Annabelle & Vilas & 79 & 50 & & $\mathrm{X}$ \\
\hline Big Carr & Oneida & 85 & 35 & & \\
\hline Birch & Vilas & 205 & 44 & $\mathrm{X}$ & $\mathrm{X}$ \\
\hline Black $^{\mathrm{a}}$ & Ashland, Sawyer & 54 & 48 & & $\mathrm{X}$ \\
\hline Chippewa $^{a}$ & Bayfield & 111 & 52 & & $\mathrm{X}$ \\
\hline Circle Lily & Iron, Vilas & 88 & 52 & & $\mathrm{X}$ \\
\hline Clear & Oneida & 353 & 33 & $\mathrm{X}$ & \\
\hline Fisher & Iron & 178 & 55 & & $\mathrm{X}$ \\
\hline Hancock & Oneida & 105 & 56 & & $\mathrm{X}$ \\
\hline Harris & Vilas & 216 & 38 & & $\mathrm{X}$ \\
\hline Hasbrook & Oneida & 124 & 34 & & \\
\hline Horsehead & Vilas & 101 & 46 & & $\mathrm{X}$ \\
\hline Jute & Vilas & 77 & 38 & $\mathrm{X}$ & \\
\hline Kentuck & Forest, Vilas & 405 & 48 & $\mathrm{X}$ & \\
\hline Little Sissabagama $^{a}$ & Sawyer & 125 & 43 & & \\
\hline Long & Iron & 150 & 45 & $\mathrm{X}$ & $\mathrm{X}$ \\
\hline Mineral $^{\mathrm{a}}$ & Ashland & 92 & 41 & & \\
\hline $\operatorname{Mud}^{\mathrm{a}}$ & Sawyer & 188 & 44 & & \\
\hline North Twin & Vilas & 1,162 & 43 & $\mathrm{X}$ & \\
\hline Oxbow & Vilas & 212 & 44 & $\mathrm{X}$ & $\mathrm{X}$ \\
\hline Pelican & Oneida & 1,435 & 48 & $\mathrm{X}$ & $\mathrm{X}$ \\
\hline Pine & Iron & 121 & 49 & $\mathrm{X}$ & \\
\hline Razorback & Vilas & 154 & 40 & & $\mathrm{X}$ \\
\hline Roberts & Forest & 176 & 42 & $\mathrm{X}$ & $\mathrm{X}$ \\
\hline Sevenmile & Forest, Oneida & 210 & 45 & $\mathrm{X}$ & $\mathrm{X}$ \\
\hline Snipe & Vilas & 87 & 50 & & \\
\hline Spider & Oneida & 50 & 42 & & \\
\hline
\end{tabular}

${ }^{a}$ Spawning site data for these lakes are from Rust et al. (2002).

repeat observations of individual Muskellunge, which could be common due to spawning ground fidelity (Crossman 1990). Horsehead Lake was surveyed on April 28, 2007, and on May 6,11 , and 16, 2008, in order to compare spawning site locations throughout the 2008 spawning period and between 2007 and 2008. Only data from the 2007 Horsehead Lake survey were included in the habitat selection analysis and MaxEnt model.

Within $11 \mathrm{~d}$ of the spotlighting survey, each potential spawning site was searched for eggs by using a D-frame net until a Muskellunge egg was found or until a search effort of 1.5 person-hours had been achieved (after Zorn et al. 1998). This time frame ensured that deposited eggs would not have hatched before the search, as hatch times were $12-25 \mathrm{~d}$ based on temperatures measured during spotlighting and degreeday estimates (Westers and Stickney 1993). Due to a high number of adult Muskellunge observed at North Twin Lake, egg searches at that site were limited to 1 person-hour. Oehmcke et al. (1958) described Muskellunge behavior as broadcast spawning over "several hundred yards." We observed Muskellunge spawning over distances of more than $140 \mathrm{~m}$, so Muskellunge eggs found within $200 \mathrm{~m}$ of a site were considered a verification of spawning. Egg redistribution was assumed to be negligible in comparison with the size of the spawning ground, as Zorn et al. (1998) measured low water velocities at Muskellunge spawning habitats in similar northern Wisconsin lakes. A subsample of eggs was hatched and grown for $30 \mathrm{~d}$ to verify identification. All of the spawning sites that were included in habitat selection analysis and modeling were verified based on positive identification of Muskellunge eggs.

Spawning site data from Rust et al. (2002) that met our study's stocking criteria were added to our survey data. We used a comparable spotlighting methodology — searching a similar radius with handheld spotlights at comparable temperatures. Rust et al. (2002) searched areas less than $1.0 \mathrm{~m}$ deep, whereas we searched areas less than $1.5 \mathrm{~m}$ deep. We did not measure depth directly, but we observed that most 
Muskellunge were located in depths less than $1.0 \mathrm{~m}$. Both studies confirmed spawning sites by conducting egg surveys with D-frame nets. One of us (J. S. Diana) assisted in study design and data collection for both the Rust et al. (2002) study and the present research, thus ensuring that methodologies were similar and that data were comparable.

Habitat data.-A series of habitat maps was created for variables that were hypothesized to be predictive for Muskellunge spawning sites. We collected data that were specific to sites within lakes and data at the whole-lake scale (Table 2). Existing GIS data were used to generate maps for some habitat variables, including slope, bathymetric curvature, aspect, nearby shallow area, effective fetch, groundwater potential, distance to the nearest inflowing or outflowing stream, and riparian land cover. As described below, we conducted on-the-ground habitat evaluation to map other habitat variables, including emergent vegetation, SAV, and substrate.

Bathymetric features, such as slope, curvature, aspect, and the size of nearby shallow areas, may indirectly influence Muskellunge spawning habitat selection through relationships with physical characteristics (e.g., temperature and current; Wetzel 2001) and biological habitat characteristics (e.g., vegetation distribution; Chambers 1987). Bathymetric maps were obtained from the Wisconsin Department of Natural Resources (WDNR 1939-1978), and the shoreline and $\sim 1.5$-m contours were digitized. A triangulated irregular network bathymetric model was created in ArcGIS version 9.2 (Environmental Systems Research Institute, Redlands, California) from which 5-m raster data sets were derived for slope,

TABLE 2. List of candidate variables considered for inclusionduring the variable selection step in MuSKIE model development $(\mathrm{TSI}=$ trophic state index).

\begin{tabular}{lcc}
\hline Variable & $\begin{array}{c}\text { Within-lake } \\
\text { scale }\end{array}$ & $\begin{array}{c}\text { Whole-lake } \\
\text { scale }\end{array}$ \\
\hline Aspect & $\mathrm{X}$ & \\
Bathymetric curvature & $\mathrm{X}$ & \\
Distance to outflowing stream & $\mathrm{X}$ & \\
Distance to inflowing stream & $\mathrm{X}$ & \\
Effective fetch & $\mathrm{X}$ & \\
Emergent vegetation & $\mathrm{X}$ & \\
Groundwater potential & $\mathrm{X}$ & \\
Nearby shallow area & $\mathrm{X}$ & \\
Riparian land cover & $\mathrm{X}$ & \\
Slope & $\mathrm{X}$ & \\
Submersed aquatic vegetation & $\mathrm{X}$ & \\
Substrate & $\mathrm{X}$ & \\
Carlson's TSI & & $\mathrm{X}$ \\
Shoreline development index & & $\mathrm{X}$ \\
Maximum depth & & $\mathrm{X}$ \\
Northern Pike presence & & $\mathrm{X}$ \\
\hline
\end{tabular}

bathymetric plan curvature, and aspect. Slope was categorized as shallow $(<10 \%)$, moderate $(10-20 \%)$, steep $(20-40 \%)$, or very steep ( $>40 \%)$. Bathymetric curvature was calculated as the second derivative of the nearshore bathymetric surface, perpendicular to the direction of the slope. A high bathymetric curvature value represents a concave feature (e.g., a bay), while a low value represents a convex feature (e.g., the tip of a peninsula). Bathymetric curvature was categorized as very convex (less than -0.015 per meter), convex (between -0.015 and 0 per meter), straight $(0$ per meter $)$, concave (between 0 and 0.03 per meter), and very concave ( $>0.03$ per meter). Aspect represented the side of the lake a spawning area was on, based on the bathymetry. Therefore, $180^{\circ}$ indicated a slope on the southern shore facing north. For the GIS model, aspect was transformed into a measure of east-west aspect using sine transformation and into north-south aspect using cosine transformation (Zar 1999). Nearby shallow area was defined as the total area between the $0-\mathrm{m}$ and $\sim 1.5$-m contours within $100 \mathrm{~m}$ of a $15-\times 15-\mathrm{m}$ grid cell; for the habitat selection analysis, nearby shallow area was categorized as follows: no flats $\left(<3,375 \mathrm{~m}^{2}\right)$, small flats $\left(3,375-6,750 \mathrm{~m}^{2}\right)$, large flats $\left(6,750-11,250 \mathrm{~m}^{2}\right)$, and very large flats $\left(>11,250 \mathrm{~m}^{2}\right)$.

Similarly, wind fetch may also indirectly influence the physical (Wetzel 2001) and biological (Chambers 1987) characteristics of Muskellunge spawning habitat. Effective fetch, an indicator of potential wind and wave exposure, was calculated using the fetch model developed by Rohweder et al. (2008). Maps from WDNR (2007) were used to calculate fetch for each compass direction in $10^{\circ}$ increments for each cell. The number of hourly wind energy measurements during May from 1973 to 2004 was determined for wind energies of $0-5$, 5-12, 12-20, and $>20 \times 1,000$ metric tons for each direction in $10^{\circ}$ increments. Data for Rhinelander, Wisconsin, were provided by the National Weather Service and National Climate Data Center (NWS and NCDC 2009) and were applied to each study lake. The proportions of hourly measurements were multiplied by the corresponding wind energy for that category (2.5, 8.5, 16, and $20 \times 1,000$ metric tons, respectively), summed, and standardized to produce a weight for that $10^{\circ}$ increment. The restricted fetch value (Smith 1991) was multiplied by its respective wind speed weight for each $10^{\circ}$ increment, and the wind-energy-weighted average fetch (hereafter, "effective fetch") was calculated. Effective fetch was categorized as very sheltered $(<39 \mathrm{~m})$, sheltered $(39-56 \mathrm{~m})$, exposed $(56-78 \mathrm{~m})$, and very exposed $(>78 \mathrm{~m})$.

Previous research has suggested the importance of groundwater flow in creating Muskellunge spawning habitat (Dombeck et al. 1984; Zorn et al. 1998). The potential for groundwater flow was determined using a GIS-based application of Darcy's Law (Baker et al. 2003). Groundwater potential was categorized as high recharge $(<150 \mathrm{~m} / \mathrm{d})$, recharge $(150$ to $0 \mathrm{~m} / \mathrm{d})$, discharge $(0-100 \mathrm{~m} / \mathrm{d})$, high discharge $(100$ $300 \mathrm{~m} / \mathrm{d})$, and very high discharge $(>300 \mathrm{~m} / \mathrm{d})$. Thiessen polygons were used to extrapolate shoreline values of 
groundwater potential, so each grid cell in the lake represented groundwater potential at the nearest point on the shoreline (Nohner 2009).

Muskellunge have been described as sometimes spawning near streams (Dombeck 1979; Dombeck et al. 1984; Zorn et al. 1998). To determine whether Muskellunge selected spawning sites near streams, we created two separate maps to calculate distance from each spawning site to the nearest inflowing or outflowing stream. Cost distance calculations were used to ensure that the distance represented the shortest possible distance traveled through the water. A threshold of $250 \mathrm{~m}$ was used to classify each grid cell as "near a stream inlet" or "near an outflowing stream" for purposes of the habitat selection analysis; our observations indicated that lotic influence on habitat was greatly decreased at this distance and that it was an upper estimate for the distance of broadcast spawning. The inflow and outflow variables were represented by a cost distance (m) for the GIS model, and all distances greater than $1 \mathrm{~km}$ were coded as $1 \mathrm{~km}$.

Land cover has previously been used to predict Muskellunge spawning success at the whole-lake level and is related to in-lake habitat, such as large woody debris (Rust et al. 2002). We used data from the 30-m-resolution National Land Cover Dataset (Fry et al. 2011), which contains detailed descriptions of the land cover classes (developed, open space; deciduous forest; evergreen forest; mixed forest; cultivated crops; woody wetlands; shrub/scrub; and herbaceous wetlands). Thiessen polygons were used to extrapolate shoreline values (Nohner 2009), so each grid cell in the lake was assumed to represent riparian land cover at the nearest point on the shoreline.

Habitat surveys for SAV, emergent vegetation, and substrate were conducted to characterize the habitat available to spawning Muskellunge. For each survey, a boat followed an estimated $1.5-\mathrm{m}$ depth contour along the entire shoreline, and the major vegetation and substrate type along the entire crosssectional line from the boat to shore were visually classified. This classification was recorded as a single polyline along the $1.5-\mathrm{m}$ depth contour for segments of contiguous habitat types. These polylines were then attributed to the shallow area that they represented, and a habitat map of the shallow area for each lake was produced. Since previous research has emphasized the structural aspect of aquatic vegetation for egg survival (Dombeck et al. 1984), vegetation was categorized according to structural groups (Tables 3,4). The minimum criterion for recording the presence of SAV was presence over a majority of the cross section, while emergent vegetation was recorded if it was present at all. Inorganic substrates were visually categorized using a modified Wentworth scale as silt, sand, gravel, cobble, and boulder (Allan 1995, after Cummins 1962). Muck was included in the silt category. The final substrate category consisted of coarse particulate organic matter (CPOM), such as leaves and woody debris. Due to equipment failure, substrate and vegetation data from approximately half of the lakes were lost. Surveys were conducted between May 28 and June 16, 2008, in the approximate order that spawning occurred in each lake based upon surface water temperatures. Among the lakes surveyed for spawning Muskellunge in 2008, the maximum time that elapsed between spotlighting surveys and habitat mapping was $24 \mathrm{~d}$.

Muskellunge spawning success may be influenced by whole-lake-scale characteristics (Dombeck et al. 1986; Rust et al. 2002). We included whole-lake-scale variables in the MaxEnt model to account for potential differences in habitat selection between different lake types. Maximum depth was obtained from bathymetric maps (WDNR 1939-1978). Shoreline development (Wetzel 2001) was calculated using shorelines created from 1:24,000-scale maps (WDNR 2007). Carlson's trophic state index (TSI), where higher values indicate a more eutrophic status, was calculated by LakeSat (2001) using satellite-measured Secchi depth measurements. The presence/absence of Northern Pike Esox lucius in each lake as determined by WDNR (2009) was included as a variable because interspecific competition has been hypothesized (Strand 1986).

Habitat selection and MaxEnt modeling required information on available habitat in each lake. We used ArcGIS to generate 2,000 randomly placed points between the shoreline and the $1.5-\mathrm{m}$ contour in each lake to subsample environmental data. These points were attributed with the underlying

TABLE 3. Characteristics used to categorize submersed aquatic vegetation in the study lakes.

\begin{tabular}{lll}
\hline Category & Description & Common examples \\
\hline Complex leaf & $\begin{array}{c}\text { Complex or brushlike leaves; leaves or leaflets } \\
\text { typically short }\end{array}$ & $\begin{array}{c}\text { Coontail Ceratophyllum demersum, Canadian } \\
\text { waterweed Elodea canadensis, and } \\
\text { shortspike watermilfoil Myriophyllum } \\
\text { sibiricum }\end{array}$ \\
$\begin{array}{l}\text { Simple leaf } \\
\text { Mat-forming and grasses }\end{array}$ & $\begin{array}{l}\text { Pondweeds Potamogeton spp. } \\
\text { Simple, flattened leaves } \\
\text { Absent }\end{array}$ & $\begin{array}{c}\text { Needle spikerush Eleocharis acicularis, } \\
\text { American eelgrass Vallisneria americana, } \\
\text { and stoneworts Chara spp. }\end{array}$ \\
\hline
\end{tabular}


TABLE 4. Characteristics used to categorize emergent aquatic vegetation in the study lakes.

\begin{tabular}{|c|c|c|}
\hline Category & Description & Common examples \\
\hline Sedges & Triangular stem in cross section & $\begin{array}{l}\text { Sedges Carex spp., river bulrush Schoenoplectus fluviatilis, } \\
\text { and rattlesnake mannagrass Glyceria canadensis }\end{array}$ \\
\hline Rushes & Circular stem in cross section; few leaves & $\begin{array}{l}\text { Common spikerush Eleocharis palustris, hardstem bulrush } \\
\text { Schoenoplectus acutus, softstem bulrush Schoenoplectus } \\
\text { tabernaemontani, Canadian rush Juncus canadensis, and } \\
\text { common rush Juncus effusus }\end{array}$ \\
\hline Cattails & $\begin{array}{l}\text { Circular in cross section; tall, sword-shaped } \\
\text { leaves }\end{array}$ & $\begin{array}{l}\text { Broadleaf cattail Typha latifolia and narrowleaf cattail } \\
\text { Typha angustifolia }\end{array}$ \\
\hline Floating leaf & $\begin{array}{l}\text { Floating leaves or broad leaves that are } \\
\text { supported at or near the surface }\end{array}$ & $\begin{array}{l}\text { American white waterlily Nymphaea odorata, variegated } \\
\text { yellow pond-lily Nuphar variegata, pickerelweed } \\
\text { Pontederia cordata, floating pondweed Potamogeton } \\
\text { natans, and broadleaf arrowhead Sagittaria latifolia }\end{array}$ \\
\hline Absent & $100 \%$ absent & \\
\hline
\end{tabular}

habitat data and were used to represent the available spawning habitat.

Spawning habitat selection.-We analyzed habitat selection by using conventional statistics to produce readily interpretable habitat selection coefficients and to provide a statistical justification for a variable's inclusion in the MaxEnt model. Spawning habitat selection by Muskellunge was determined for each lake by comparing the proportion of spawning sites to the proportion of available spawning habitat in each lake for each habitat category. In addition, selection for three-way combinations of habitat categories from different variables (e.g., a habitat with shallow slope, muck substrate, and sheltered effective fetch) was also analyzed. To limit the number of statistical tests and potential type I error, these interactions were only analyzed on lakes with greater than $5 \%$ of available habitat in a category. Three-way habitat combinations provided the maximum number of combinations that could be analyzed based upon computing limitations and the number of spawning sites in each combination. The Wilcoxon signedrank test was used to compare the proportion of spawning sites to the proportion of available spawning habitat for each variable, assuming that lakes were similar enough to be considered replicates. Significance for all statistical tests was determined using an $\alpha$ value of 0.05 . Rare habitat categories often had no spawning sites, so the proportional area for each category was squared to account for an observed decrease in SD among higher values (Zar 1999).

Muskellunge spawning habitat selection was analyzed in relation to Carlson's TSI to test whether spawning habitat selection was consistent across lakes of differing trophic status. The habitat selection analysis described above directly assessed the difference between the proportion of spawning sites and the proportion of available spawning habitat in each lake, whereas an investigation of relationships with trophic status required a single composite index of habitat selection. Selection for each habitat type in each lake was calculated using Ivlev's (1961) index of electivity: $E=(r-p) /(r+p)$, where $r=$ the proportion of verified spawning sites and $p=$ the proportion of available spawning habitat. The $E$-values for each lake were then compared to the corresponding Carlson's TSI values by using Spearman's rank correlation coefficient $\left(r_{s}\right)$.

Spawning habitat model.-Muskellunge spawning sites were predicted by using the machine learning program MaxEnt (Phillips et al. 2006, 2008). MaxEnt has been used to predict species distributions of plants, amphibians, birds, and reptiles based on geospatial habitat data (Phillips and Dudík 2008). MaxEnt models predict species distributions using only species presence data. The program offers the option for raw, cumulative, or logistic outputs, and it produces an output map in raster format. We chose to map raw output, with each cell representing the relative probability of Muskellunge spawning presence such that all cells summed to 1.0. The MaxEnt program iteratively fits a species' predicted distribution to environmental variables, and it determines coefficients for habitat variables that maximize likelihood after applying a penalty that reduces overfitting (Merow et al. 2013). The output data for this study were in the form of a 5-m raster grid file, with the value of each cell being an index of the relative predicted probability of presence (Phillips and Dudík 2008). Although the 5-m resolution is finer than that of the land cover or nearby shallow area, it was selected to accommodate the narrow bands of littoral habitat that would have been precluded by a more coarse resolution.

We trained a MaxEnt model by using the spawning site and available spawning habitat data sets described above; hereafter, we refer to this MaxEnt model as the Muskellunge spawning $k$-fold-validated index of electivity (MuSKIE) model. Since the habitat analysis produced evidence for differential habitat selection in different lake types, we also tested four variables (Carlson's TSI, maximum depth, Northern pike presence, and shoreline development index) as whole-lake 
variables. All model parameters were initially set to the MaxEnt program's default settings, as was advised by Phillips and Dudík (2008).

Collinearity between habitat variables was detected (see Supplementary Table S.1 in the online version of this paper), but moderately collinear variables still may provide unique information. Pairs of categorical variables with an $r_{s}$ value greater than 0.50 (Posa and Sodhi 2006) or pairs of continuous variables with a Pearson's product-moment correlation coefficient (Pearson's $r$ ) greater than 0.70 (Geiger et al. 2010) were not simultaneously used in the MaxEnt model. No variables met these criteria; therefore, all variables were initially included in the selection process.

Model selection and evaluation were performed using an area-under-the-curve (AUC) analysis because it is threshold independent and provides an integrated measure of model accuracy (Deleo 1993). A point $(x, y)$ on the AUC plot can be interpreted as follows: "When a model identifies the most likely $x$ percent of the available spawning habitat, that area includes $y$ percent of the spawning sites." Integrating these values across all thresholds $x$ provides a threshold-independent measure of model performance (i.e., the AUC). An AUC value of 0.5 represents the predictive power of a random model; a value of 1.0 is ideal.

Test AUC values were calculated in a manner similar to the $k$-fold validation process (Elith et al. 2011) except that the data were partitioned by using individual lakes instead of random partitions. A partial model was trained on 27 lakes and then the test AUC was calculated for its application to the remaining lake. After test AUC values were calculated for each of the 28 lakes, the test AUC values were averaged to produce the 28 -fold cross-validation test AUC (hereafter, $\left.\mathrm{AUC}_{\text {test }}\right)$. Test AUC values for individual lakes were analyzed using the Mann-Whitney $U$-test to evaluate a difference in the mean from that of a hypothetical random model with an AUC of 0.5 (Yost et al. 2008).

MaxEnt model selection was performed by forward selection of variables to maximize $\mathrm{AUC}_{\text {test }}$. After preliminary variable selection, all possible combinations of the feature types (linear, product, hinge, quadratic, and threshold feature types) were tested. Feature types are different functional forms that enable the model to represent complex relationships between covariates. Linear, product, and hinge feature types were found to maximize $\mathrm{AUC}_{\text {test }}$ and were included in the final model. After selecting variables for inclusion in the model, we trained eight trial models to investigate the impacts of regularization on model performance. Regularization can be modified through a regularization coefficient $(\beta)$ - a constant that is multiplied by regularization values that were previously optimized for each feature class (Phillips and Dudík 2008). Low regularization values tend to result in models with more variables and more complex response curves, while higher regularization values result in fewer variables and smoother response curves. We plotted model performance (i.e., $\mathrm{AUC}_{\text {test }}$ ) against varied $\beta$ values $(0.1,0.5,0.9,1.0,1.1,1.5,2.0$, and 3.0) and selected the $\beta$ value at the peak of the curve (Phillips and Dudík 2008). The final MuSKIE model was trained using the entire 28-lake data set, and $\mathrm{AUC}_{\text {train }}$ was calculated using those pooled data.

The extent to which each variable contributed to the MuSKIE model was estimated using a jackknife test of variable importance on training data (Yost et al. 2008). This technique measures the training gain from a model based solely on a given variable in comparison with a model based on all variables except that variable of interest. Training gain, which represents the increase in likelihood between the average spawning site and a uniform probability distribution, was calculated for each model using pooled data for spawning sites and available spawning habitat. The contribution of the variables included in the final model was investigated by fitting two MaxEnt models using only variables at the within-lake and whole-lake scales.

\section{RESULTS}

Our spotlighting surveys identified 388 potential Muskellunge spawning sites in 2007 and 2008; of these, 282 (73\%) were verified by collection of Muskellunge eggs. On average, spawning sites were verified after 45 person-minutes of effort. Surface water temperatures ranged from $7^{\circ} \mathrm{C}$ to $15^{\circ} \mathrm{C}$ during spotlighting surveys. Although surveys focused on Muskellunge spawning in depths less than $1.5 \mathrm{~m}$, there was one observation of a Muskellunge at a depth greater than $1.5 \mathrm{~m}$. No eggs were found in the shallow water near that site.

\section{Spawning Habitat Selection}

Most Muskellunge spawning sites were located in areas with no SAV (median value from individual lakes $=83 \%$; Figure 1) or emergent vegetation (52\%), that had sandy substrates $(65 \%)$, and that were adjacent to riparian woody wetlands $(40 \%)$. However, this spawning habitat usage was often heavily dependent upon the available habitat in each lake. Muskellunge showed selection against sites that were adjacent to herbaceous wetlands (Wilcoxon's signed rank test: $T^{-}=0$, $n=11, P=0.004$ ) or to developed, open riparian land cover $(T=65, n=23, P=0.003)$. Muskellunge selected against complex-leafed vegetation, such as coontail Ceratophyllum demersum, Canadian waterweed Elodea canadensis, and shortspike watermilfoil Myriophyllum sibiricum $\left(T^{-}=0, n=\right.$ $9, P=0.010$ ). The majority of spawning sites occurred in areas classified as having no SAV, although selection for this habitat type narrowly failed to meet the statistical significance criterion. Substrates without SAV were selected more commonly in more eutrophic lakes $\left(r_{s}=0.755, \mathrm{df}=9, P=0.010\right.$; Figure 2). Selection against mat-forming vegetation, such as stoneworts Chara spp., was also observed more commonly in 


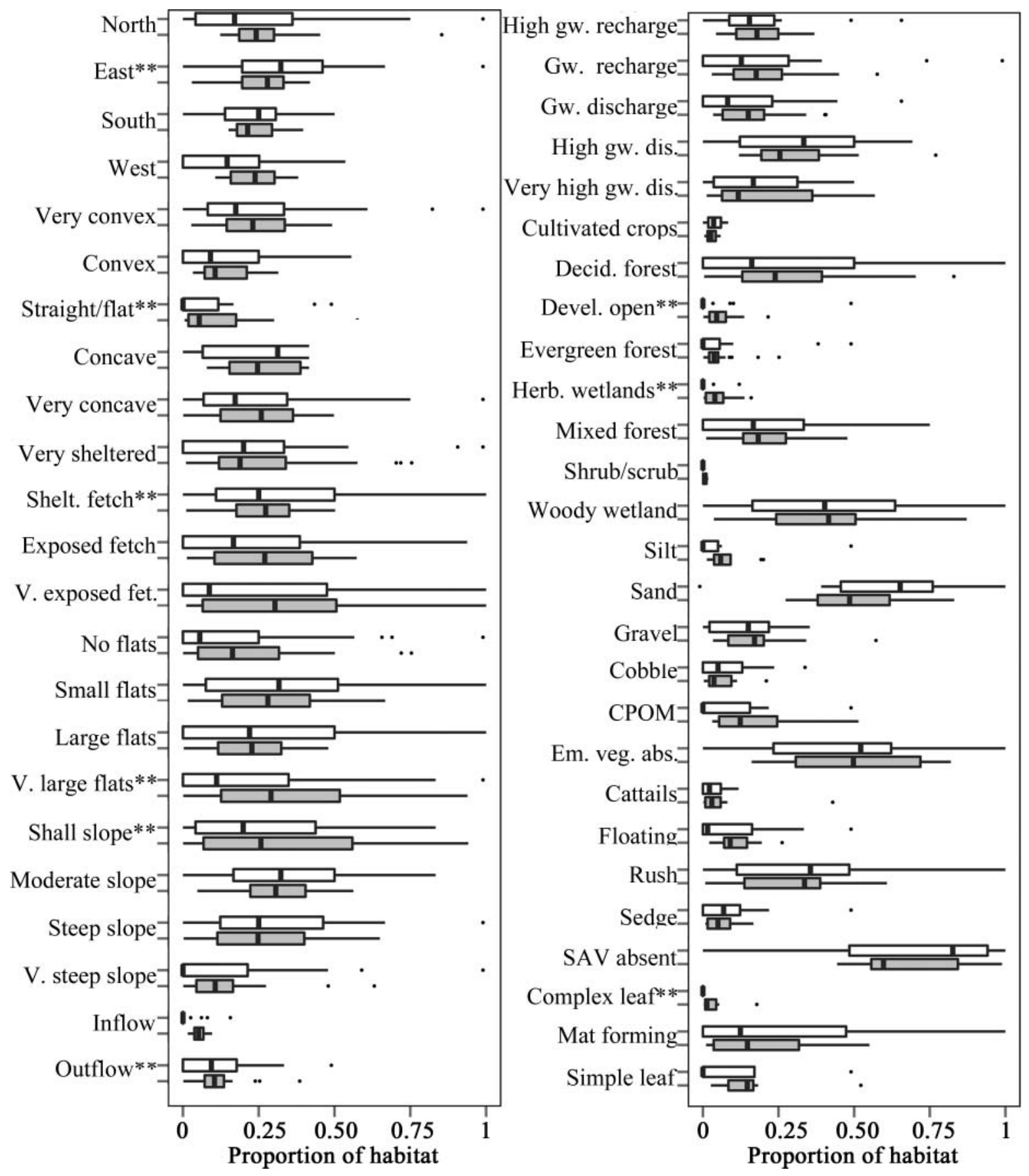

FIGURE 1. Muskellunge spawning habitat selection in 28 northern Wisconsin lakes. Proportions of verified spawning sites (white bars) from spotlighting surveys and available spawning habitat (gray bars) were calculated for each lake and are indicated by position on the $x$-axis (line within box $=$ median; ends of box $=$ interquartile range; ends of whiskers $=95 \% \mathrm{CI}$ for the median; dots $=$ outliers). Estimates from the Wilcoxon signed-rank test indicate positive or negative habitat selectivity and are evident by the difference between the proportion of spawning sites (white bars) and available spawning habitat (gray bars). Significant differences $(P \leq 0.05)$ are indicated by asterisks. The $y$-axis labels (starting at the upper portion of the left panel) describe the following: aspect (north, east, south, or west); bathymetric curvature (very convex, convex, straight/flat, concave, or very concave); effective fetch (very sheltered, sheltered [shelt.], exposed, or very [v.] exposed); nearby shallow area (no flats, small flats, large flats, or very large flats); slope (shallow [shall.], moderate, steep, or very steep); distance to inflowing stream (inflow); distance to outflowing stream (outflow); groundwater (gw.) potential (high recharge, recharge, discharge, high discharge, or very high discharge); riparian land cover (cultivated crops, deciduous [decid.] forest, developed [devel.] open space, evergreen forest, herbaceous [herb.] wetlands, mixed forest, shrub/scrub, or woody wetlands); substrate (silt, sand, gravel, cobble, or coarse particulate organic matter [CPOM]); emergent vegetation (em. veg.; absent [abs.], cattails, floating, rushes, and sedges); and submersed aquatic vegetation (SAV; absent, complex leaf, mat forming, and simple leaf). 


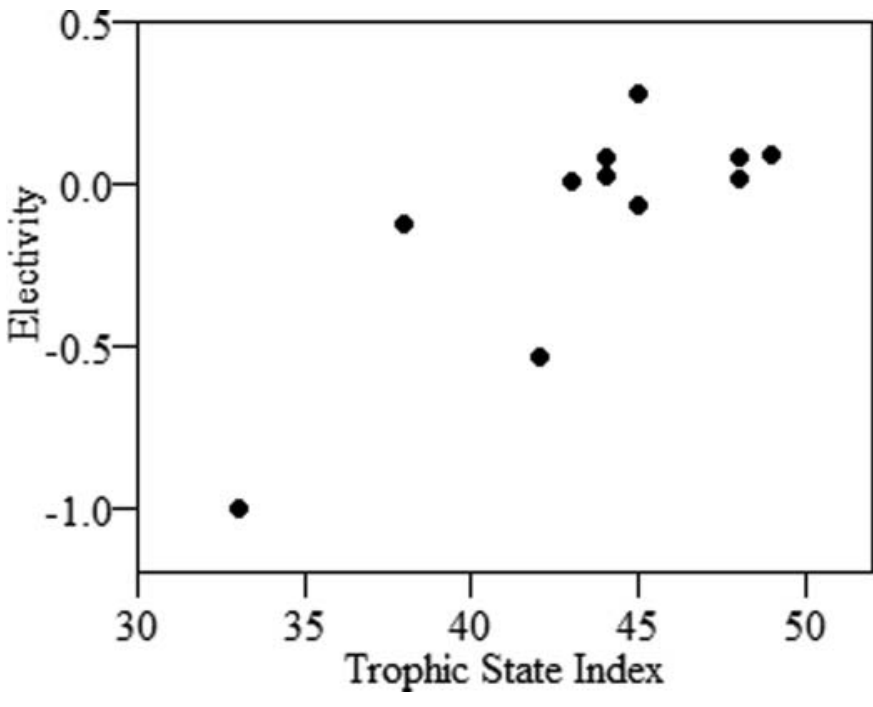

FIGURE 2. Muskellunge spawning site selection (calculated with Ivlev's electivity index) for areas without submersed aquatic vegetation plotted against Carlson's trophic state index (TSI) for 11 northern Wisconsin lakes. A significant positive correlation between electivity and TSI was indicated (Spearman's rank correlation coefficient $r_{s}=0.755, \mathrm{df}=9, P=0.010$ ).

eutrophic lakes, although this was not statistically significant $\left(r_{s}=-0.616, \mathrm{df}=8, P=0.065\right)$.

Muskellunge selected against habitats located within $250 \mathrm{~m}$ of an outflowing stream $\left(T^{-}=39, n=20, P=0.013\right)$, but there was no apparent selection for spawning locations near stream inlets $\left(T^{-}=102, n=19, P=0.888\right)$. Muskellunge tended to avoid large flats for spawning; they selected against shallow-sloping bathymetry ( $T=75, n=24, P=0.023)$ and against areas with an abundance of nearby shallow area $\left(T^{-}=\right.$ $57, n=23, P=0.018)$. Areas with sheltered effective fetch $\left(T^{+}=288, n=27, P=0.050\right)$ or on the eastern side of the lake $\left(T^{+}=315, n=28, P=0.020\right)$ were selected. Areas with no bathymetric curvature were selected against $\left(T^{-}=73, n=\right.$ $26, P=0.007)$, especially in more eutrophic lakes.

Selection estimates were also investigated for combinations of variables (Table 5). Avoidance was not detected for any combination of variables. However, Muskellunge selected for areas with moderate slopes, small flats, and concave shorelines (bays). They also selected for shallow slopes near riparian deciduous forests with very concave shorelines.
This evidence for interactions and suites of spawning habitat characteristics required the development of a MaxEnt model in order to generate adequate predictions of where Muskellunge spawn.

\section{MuSKIE model}

The MuSKIE model was created in MaxEnt using 393 verified spawning sites from 28 lakes using data from the surveys described in this paper and Rust et al. (2002). Variables with significant evidence for Muskellunge spawning habitat selection as described above were tested for potential inclusion in the model: aspect, bathymetric curvature, effective fetch, groundwater potential, nearby shallow area, Northern Pike presence, slope, distance to the nearest inflowing or outflowing stream, riparian land cover, and SAV. The best-performing MaxEnt model predicted the locations of Muskellunge spawning habitat using four within-lake variables (nearby shallow area, distance to an outflowing stream, effective fetch, and cos [aspect]) and three whole-lake variables (shoreline development index, maximum depth, and Carlson's TSI).

Variable response curves provide an illustration of how the probability of spawning is influenced by lake-scale variables across their range, holding all other variables at their average values (Figure 3). Habitats between 100 and $400 \mathrm{~m}$ from outflowing streams were more likely to be used as spawning habitat. Habitats with large effective fetches or large shallow flats were predicted as less likely to be used as spawning habitat. The response curve for cos(aspect) was relatively level across its range, indicating weak selection by Muskellunge based on whether the location faced the north or the south. A rise in the relative probability of spawning when the shoreline development is high corresponds to high densities of Muskellunge spawning sites in Mud Lake. The variable response curves in Figure 3 indicate the relative probability of spawning as predicted by the model after accounting for all interactions with other variables. The closeness of the fit in the probabilities for available spawning habitat points indicates where that variable was most predictive: near outflowing streams; in areas with high effective fetches; and for sites surrounded by very large areas of shallow flats. The relative contribution of each habitat variable to the model based on training gain is presented in Table 6. Overall training gain was 0.288 . These results suggest that the nearby shallow area variable was the most important

TABLE 5. Muskellunge spawning habitat selection described by three-way combinations of categorical variables. Three-way combinations with significant selection $(P<0.05)$ are listed in descending magnitude of selection estimates, which were calculated using the Wilcoxon signed-rank test. Proportions of spawning sites and available spawning habitat were calculated for each lake, and the median proportion from the individual lakes is presented.

\begin{tabular}{lcccccc}
\hline $\begin{array}{l}\text { Spawning } \\
\text { sites }(\%)\end{array}$ & $\begin{array}{c}\text { Available spawning } \\
\text { habitat }(\%)\end{array}$ & $\begin{array}{c}\text { Habitat selection } \\
\text { estimate }\end{array}$ & Slope & $\begin{array}{c}\text { Nearby shallow } \\
\text { area }\end{array}$ & $\begin{array}{c}\text { Bathymetric } \\
\text { curvature }\end{array}$ & $\begin{array}{c}\text { Riparian land } \\
\text { cover }\end{array}$ \\
\hline 16.7 & 8.3 & 0.033 & Moderate & Small flats & $\begin{array}{c}\text { Concave } \\
\text { Very concave }\end{array}$ & Deciduous forest \\
\hline 14.8 & 11.3 & 0.013 & Shallow & & Dery cond
\end{tabular}



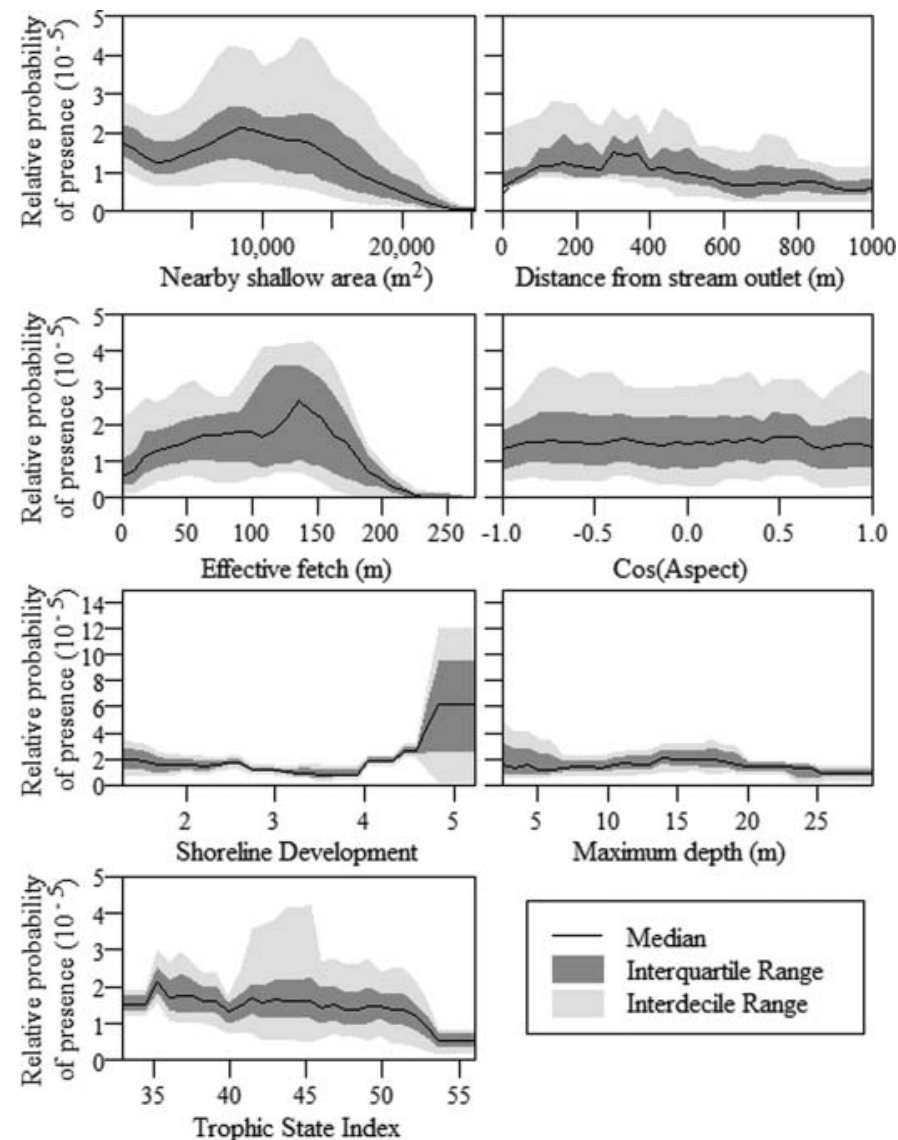

FIGURE 3. Variable response curves for the relative probability of Muskellunge spawning. Available spawning habitat was assigned a relative probability of presence by the MuSKIE model and is plotted to demonstrate the overall relationship between each variable and Muskellunge spawning after the complex interactions in the model were accounted for.

determinant of where Muskellunge spawned, with large shallow flats being avoided. Outflowing stream and effective fetch variables also contributed substantially to the model, and both were nearly equal in their contributions. North-south aspect's minimal contributions to the model provided evidence that the variable was much less directly associated with selection for spawning habitat.

Models that were created by using only within-lake variables or only whole-lake variables demonstrated the influence of variables at both scales. The MaxEnt model that included only within-lake variables had poorer performance $\left(\mathrm{AUC}_{\text {train }}\right.$ $\left.=0.651 ; \mathrm{AUC}_{\text {test }}=0.586\right)$ than the full model, indicating the importance of interactions between within-lake- and wholelake-scale variables. Variable response curves were comparable to those for the full model, except that the relative probabilities of presence at exposed effective fetches (100-200 m) were slightly higher. The MaxEnt model that used only whole-lake-scale variables generated some insight into the lake characteristics corresponding with higher relative densities of observed spawning Muskellunge. The $\mathrm{AUC}_{\text {train }}(0.660)$
TABLE 6. Relative contribution of variables to the MuSKIE model, as determined by training gain with pooled data using a jackknife test (TSI $=$ trophic state index).

\begin{tabular}{lc}
\hline Variable & $\begin{array}{c}\text { Percent } \\
\text { contribution }\end{array}$ \\
\hline Shoreline development index & 46.9 \\
Nearby shallow area & 25.8 \\
Distance from outflowing stream & 7.5 \\
Effective fetch & 6.8 \\
Maximum depth & 6.2 \\
Carlson's TSI & 4.5 \\
Cos(aspect) & 2.3 \\
\hline
\end{tabular}

for this model indicated the model's ability to identify highand low-density spawning populations in lakes, while AUC $\mathrm{Cust}_{\text {tes }}$ $(0.500)$ confirmed that a model containing only whole-lakescale data predicted spawning site locations no better than random. Variable response curves were similar to those of the full model, except that the relative probability of presence for spawning Muskellunge gradually increased as the trophic state moved from eutrophic (Carlson's TSI $=56$ ) to oligotrophic $($ Carlson's TSI $=37$ ).

Performance of candidate models in tests across different values of $\beta$ was variable (Table 7). Performance generally peaked when $\beta$ was between 1.0 and $1.1\left(\mathrm{AUC}_{\text {test }}=0.637\right)$, although there was one outlier that showed negligibly higher performance at a $\beta$ value of $0.5\left(\mathrm{AUC}_{\text {test }}=0.638\right)$. Lower $\beta$ values, such as the outlier at 0.5 , may introduce overfitting. Therefore, we interpreted these results as optimizing performance at a $\beta$ equal to 1.0 , and we selected this coefficient for the final model.

Model performance was tested against pooled training data, and $\mathrm{AUC}_{\text {train }}$ was 0.741 (Figure 4). However, the MuSKIE model was more accurately described by how it performed on an individual lake when that lake was left out of model training. The $\mathrm{AUC}_{\text {test }}$ value (an average across all lakes) was 0.637. The large SD in $\mathrm{AUC}_{\text {test }}(0.12)$ as well as the range of test AUC values (0.464-0.942) indicated that the model performed much better for some lakes than for others. The MuSKIE model performed better than a random model according to the Mann-Whitney $U$-test that compared test AUC values for the 28 individual lakes $(U=397, \mathrm{df}=27, P<0.001)$. The variance in AUC for lakes with three or fewer spawning sites was significantly greater than the variance for lakes with more than 15 spawning sites $\left(F_{10,3}=0.1604, P=0.023\right)$; two of the three lakes with AUCs below 0.5 had 10 or fewer spawning sites. There was no correlation between test AUC values for individual lakes and the shoreline development index, which was the strongest contributing variable to the model; this result indicates that the model performed similarly across the range of shoreline development index values. 
TABLE 7. Model performance (28-fold cross-validation test area under the curve $\left[\mathrm{AUC}_{\text {test }}\right]$ ) under different values of the regularization coefficient $(\beta)$. Regularization coefficients were multiplied by previously determined featuretype-specific values (Phillips and Dudík 2008) to provide an empirically precise model (low $\beta$ values) or a smoothed and simplified model (higher $\beta$ values).

\begin{tabular}{lc}
\hline$\beta$ & $\mathrm{AUC}_{\text {test }}$ \\
\hline 0.1 & 0.624 \\
0.5 & 0.638 \\
0.9 & 0.634 \\
1.0 & 0.637 \\
1.1 & 0.637 \\
1.5 & 0.636 \\
2.0 & 0.625 \\
3.0 & 0.609 \\
\hline
\end{tabular}

The single $\mathrm{AUC}_{\text {test }}$ value presents a threshold-independent measure of model performance, but performance can also be measured at any user-selected threshold. For example, if the best $20 \%$ of available habitat predicted by the model in each lake is selected, then $32 \%$ of the spawning sites, on average, will be included in that area (using cross-validation data). If the best $40 \%$ of available spawning habitat in a lake is defined, then it will include $64 \%$ of the spawning sites in the lake.

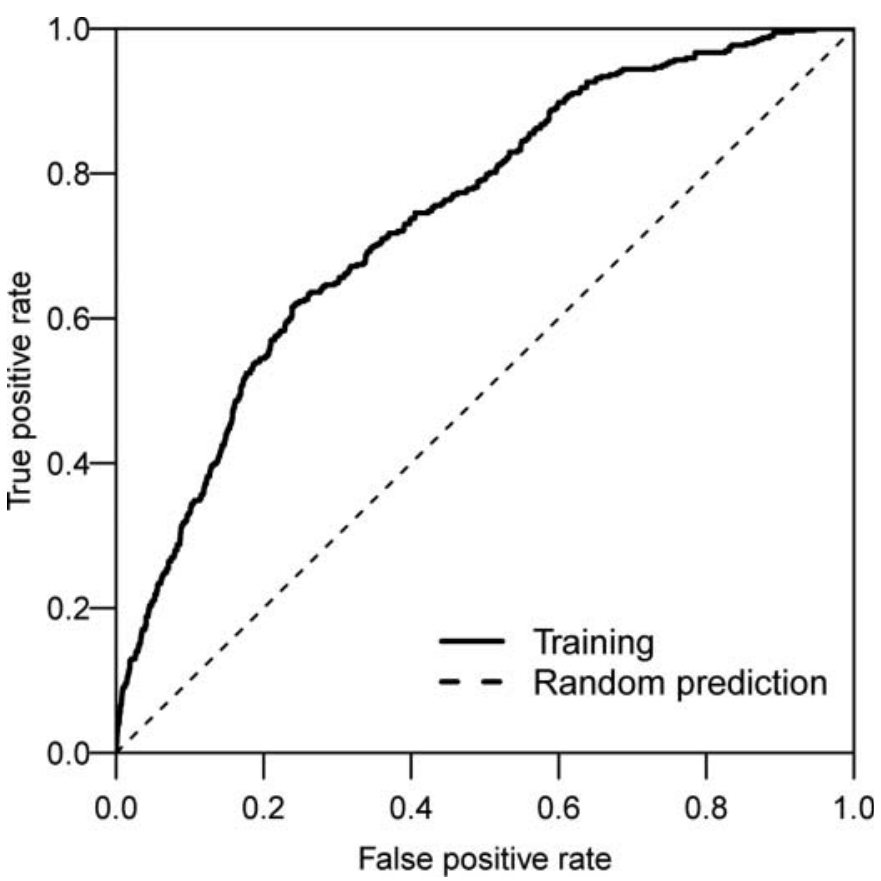

FIGURE 4. Area-under-the-curve (AUC) plots for the MuSKIE model with pooled training data $\left(\mathrm{AUC}_{\text {train }}=0.741\right)$ and for a model with predictions no better than random (AUC $=0.5$ ). A point $(x, y)$ on the AUC plot can be interpreted as follows: "When a model identifies the most likely $x$ percent of the available area as spawning habitat, that area includes $y$ percent of the spawning sites."
TABLE 8. Number of Muskellunge spawning sites that were correctly classified as present when spawning habitat was identified as the top 75th, 50th, or 25 th percentile of available spawning habitat in each lake. Separate models trained on the other 27 lakes were applied to each lake, so the data for a given lake represent an expectation of MuSKIE model performance on that lake as a "novel" lake.

\begin{tabular}{|c|c|c|c|c|}
\hline \multirow[b]{2}{*}{ Lake } & \multicolumn{3}{|c|}{ Percentile } & \multirow[b]{2}{*}{ Total } \\
\hline & 25 th & 50 th & 75 th & \\
\hline Amik & 10 & 14 & 18 & 22 \\
\hline Annabelle & 4 & 5 & 5 & 6 \\
\hline Big Carr & 4 & 5 & 6 & 6 \\
\hline Birch & 12 & 19 & 20 & 20 \\
\hline Black & 2 & 9 & 12 & 12 \\
\hline Chippewa & 7 & 11 & 12 & 12 \\
\hline Circle Lily & 5 & 6 & 14 & 16 \\
\hline Clear & 2 & 4 & 9 & 10 \\
\hline Fisher & 2 & 4 & 4 & 4 \\
\hline Hancock & 2 & 2 & 4 & 4 \\
\hline Harris & 7 & 18 & 24 & 28 \\
\hline Hasbrook & 4 & 9 & 14 & 15 \\
\hline Horsehead & 5 & 9 & 15 & 18 \\
\hline Jute & 12 & 21 & 23 & 32 \\
\hline Kentuck & 6 & 16 & 25 & 28 \\
\hline Little Sissabagama & 3 & 5 & 9 & 9 \\
\hline Long & 1 & 2 & 2 & 2 \\
\hline Mineral & 5 & 6 & 9 & 11 \\
\hline Mud & 16 & 37 & 44 & 45 \\
\hline North Twin & 4 & 11 & 13 & 13 \\
\hline Oxbow & 5 & 8 & 19 & 23 \\
\hline Pelican & 6 & 6 & 6 & 6 \\
\hline Pine & 2 & 2 & 2 & 2 \\
\hline Razorback & 1 & 6 & 8 & 9 \\
\hline Roberts & 1 & 9 & 10 & 12 \\
\hline Sevenmile & 7 & 20 & 22 & 23 \\
\hline Snipe & 0 & 1 & 2 & 2 \\
\hline Spider & 0 & 2 & 2 & 3 \\
\hline Total number & 135 & 267 & 353 & 393 \\
\hline Percent of total & 34.4 & 67.9 & 89.8 & 100 \\
\hline
\end{tabular}

Similar data for each lake are presented in Table 8, representing the model performance that could be expected for each lake if it was novel - that is, outside of the study and subject to application of the MuSKIE model for the first time.

The MuSKIE model was projected onto the 28 study lakes and overlaid with spawning site points to allow visual inspection of the model outputs. An example output from the MuSKIE model is presented for Harris Lake (Figure 5), which had an individual-lake test AUC of 0.605 . In Harris Lake, 22 of the 28 spawning sites were located in habitats with relative probabilities of $50-75 \%$. No areas in the lake were attributed with probabilities of $75-100 \%$. The range of relative probabilities varied 


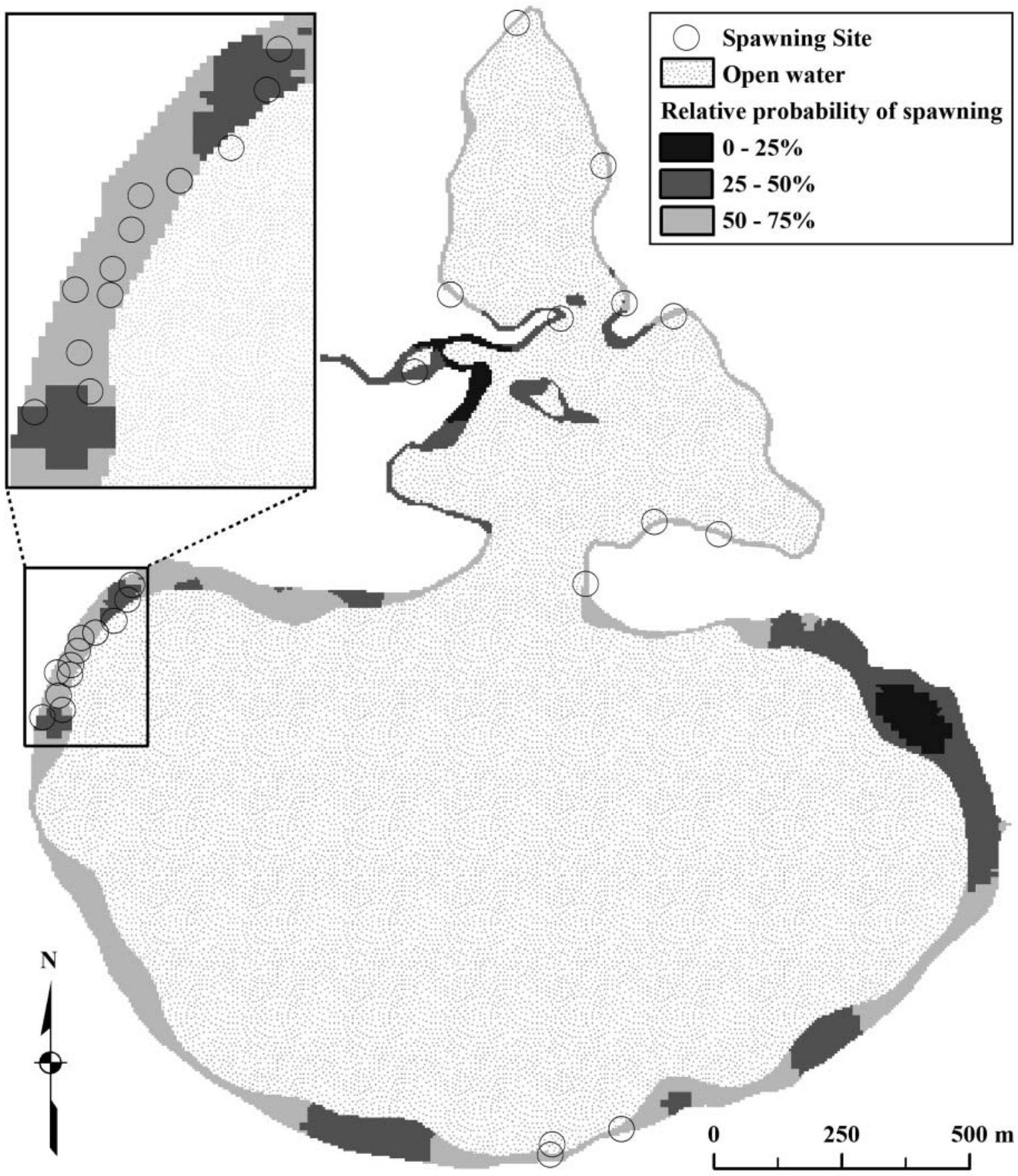

FIGURE 5. Muskellunge spawning sites and spawning habitat predictions for Harris Lake, Wisconsin. Spawning sites were identified by spotlighting surveys and confirmed by the presence of Muskellunge eggs. The MuSKIE model results are shaded to display the logistic output from MaxEnt and are interpreted for our model as an index of the relative probability of Muskellunge spawning in the shallow areas of the lake.

among lakes, since Muskellunge sighting densities and available spawning habitat quality differed depending on the lake. The lowest median relative probability for available spawning habitat was 0.157 (Pelican Lake), and the highest median relative probability was 0.637 (Big Carr Lake). The median relative probability for Harris Lake (Figure 5) was 0.476.

\section{DISCUSSION}

\section{Habitat Selection}

The first objective of this study was to describe the characteristics of habitats that Muskellunge selected for spawning. Muskellunge spawning habitat commonly had sandy substrate 
and lacked emergent vegetation or SAV; however, selection was less clear than habitat use. Selection was detected for a number of habitat classes, but no single habitat class stood out as an overwhelming determinant of spawning site selection. Our results show that across a variety of northern Wisconsin lakes, Muskellunge selected spawning habitats with multiple combinations of characteristics. These results indicate that previous descriptions of spawning habitat selection by Muskellunge may have been oversimplified. Spawning site characteristics should be interpreted in the context of the whole lake, as selection in eutrophic lakes was different than selection in mesotrophic or oligotrophic lakes. For example, Muskellunge selected sites without vegetation much more strongly in eutrophic lakes-presumably due to hypoxia, as discussed below.

The different combinations of habitat variables present at the spawning sites selected by Muskellunge must be considered in the context of their biological relevance. Low DO levels (Dombeck et al. 1984; Zorn et al. 1998; Rust et al. 2002), poor thermal habitat (Bean 1908; Oehmcke et al. 1958; Zorn et al. 1998), and predation are direct causes of egg mortality. Since many combinations of the structural, physical, and biological habitat variables described in this study might create the conditions necessary for eggs to survive and hatch, it is not surprising that Muskellunge selected a variety of habitats for spawning. Although emergent vegetation and SAV were available and utilized during spawning, there was no evidence that Muskellunge selected for aquatic vegetation. The weak selection for habitat traits supports the classification of Muskellunge as open-substratum polyphilic spawners (Kapuscinski and Farrell 2014) rather than phytophilic spawners (Balon 1975).

Our conclusion that Muskellunge selected against developed riparian habitats in 28 northern Wisconsin lakes strengthens previous evidence on the impacts of lakeshore development. Avoidance of developed riparian land cover suggests that the availability of Muskellunge spawning habitat decreases as lakeshore development increases. Christensen et al. (1996) found that residential home development decreased the amount of large woody debris in a lake, and Rust et al. (2002) concluded that developed shorelines and decreases in large woody debris had a negative effect on Muskellunge recruitment at the whole-lake scale. Our inability to detect selection for CPOM, which included both leaf litter and large woody debris, may be due to the confounding negative effects of leaf litter (Dombeck et al. 1984) and positive effects of large woody debris (Dombeck et al. 1984; Zorn et al. 1998; Rust et al. 2002). Furthermore, the loss of some CPOM data from the data set decreased the statistical power to detect selection. The lack of significant selection for CPOM does not preclude the conclusion that Muskellunge selected against developed shorelines due to the absence of large woody debris. We recommend the protection and restoration of large woody debris and other natural shoreline features in order to sustain natural reproduction of Muskellunge.
Other studies have found that complex-leafed vegetation is common in spawning grounds (Dombeck et al. 1984; Farrell et al. 1996; Monfette et al. 1996; Younk et al. 1996; Farrell 2001; Pierce et al. 2007), but our results indicated that Muskellunge exhibit selection against complex-leafed SAV. There are mechanistic explanations for why this type of vegetation may be detrimental to egg survival. Dombeck et al. (1984) found that DO was lower over living and decaying plant substrates, thus contributing to egg mortality. In our study, the complex-leafed vegetation that was mapped during habitat surveys typically comprised dense patches of overwintered plants, so the Muskellunge may have been avoiding anoxic conditions associated with those patches. The observed selection for sites without SAV in the eutrophic study lakes is consistent with this hypothesis because anoxia is more common in eutrophic systems (Wetzel 2001).

An important assumption about spawning period vegetation is that vegetation coverage was similar between the date of spawning and the date on which vegetation was mapped. Although some new vegetation undoubtedly grew during this time period, our observations were that most of the vegetation, especially SAV, had overwintered from previous years. In addition, the conclusion that spawning Muskellunge tended to avoid SAV is less sensitive to this assumption, since areas that lacked SAV during mapping would not have had SAV when eggs were deposited.

The wetlands that Muskellunge selected against were identified by the National Land Cover Dataset and tended to be large and dense. Smaller or less-dense microhabitats identified by on-the-ground observations were not always classified as wetlands in the GIS data set. The coarse GIS definitions of wetland may have skewed the wetland classification toward large, dense wetland habitats. Farrell et al. (1996) and Crane et al. (2014) observed that spawning Muskellunge selected against monotypic patches of cattails, which were highly correlated with herbaceous wetlands in our study. Substrates such as CPOM, which includes decaying leaf litter and was correlated with wetlands, are likely to experience DO microstratification or anoxia (Dombeck et al. 1984). Therefore, the selection against wetlands for spawning was likely related to the preference for oxygenated substrates and moderately dense vegetation. Previous studies of nursery habitat have also found that age-0 Muskellunge utilized low-density vegetation (Craig and Black 1986; Werner et al. 1996) and that lakes with patchy DO conditions at the substrate-water interface had increased natural reproduction (Zorn et al. 1998). Together, these results show that DO is one of the critical factors in determining Muskellunge recruitment. We recommend reducing the impacts of cultural eutrophication through riparian buffers, minimization of runoff, decreases in fertilization, and other best practices in order to minimize hypoxic conditions and improve Muskellunge spawning success.

An important consideration is that although this study focused on selectivity, some habitats that were not selected 
were commonly utilized. For example, selection for sand substrates was not detected. However, among lakes, the median proportion of spawning sites on sand substrates was $65.2 \%$ compared with $48.5 \%$ of available spawning habitat. Although there was no statistical evidence for habitat selection, it was clear that Muskellunge did utilize sand substrates, as previously observed during some studies (Dombeck et al. 1984; Monfette et al. 1996; Younk et al. 1996; Crane et al. 2014) but contrary to the results of other studies (Zorn et al. 1998). The high DO levels associated with sand substrates (Dombeck et al. 1984) likely result in higher egg survival rates in the wild, as opposed to the lower survival rates observed by Dombeck et al. (1984) in the laboratory.

Bathymetric morphometry characteristics, such as slope, fetch, aspect, and the presence of shallow flats, may influence habitat selection by Muskellunge by affecting the sediments that eggs rest upon, the DO levels, or the presence of vegetation. For example, prevailing winds out of the southwest (NWS and NCDC 2009) might increase wave action and mitigate anoxia on the eastern shorelines selected by Muskellunge.

During egg collection surveys, we observed that a number of eggs were washed onto the shoreline or were swept up in the turbulent shoreline zone. This may result in abrasion or burial of eggs and represents a mechanism whereby long effective fetches result in the mortality of Muskellunge eggs. Egg transport has not been documented for Muskellunge; however, transport and burial of Walleye Sander vitreus eggs were documented in a northern Wisconsin lake (Raabe and Bozek 2012), and some authors have suggested that egg transport contributes to Walleye egg mortality in lakes (Johnson 1961; Roseman et al. 1996; Raabe and Bozek 2012). A moderately sheltered effective fetch may provide an environment that lacks turbulence from heavy wave action while still receiving sufficient wave action to mitigate the anoxia otherwise associated with organic substrates and plants (Dombeck et al. 1984; Zorn et al. 1998; Rust et al. 2002).

Temporal changes in Muskellunge spawning site locations posed a potential concern for our analysis of data collected over multiple spawning seasons. However, spotlighting at Horsehead Lake showed little change in the distribution of spawning sites between years or throughout the spawning period. For spawning sites used during peak spawning activity in 2008 (May 16), the median distance to the nearest spawning site used in 2007 was $63.5 \mathrm{~m}$. We do not know whether particular individuals were choosing similar locations, but spawning sites for the population were in similar locations across years. The spatial distribution of spawning sites did not appear to change over the 2007 spawning period. Since temporal differences in spawning site selection were apparently minor, we determined that the data from Rust et al. (2002) were comparable to our data and were appropriate for use in our habitat selection analysis and modeling.

\section{MuSKIE Model}

We created a spawning site selection model that (1) can be employed using currently available GIS data, (2) requires minimal data collection for future model application, and (3) provides an efficient method for spawning habitat delineation. The wide range in size, trophic status, and habitat quality across lakes presented a modeling challenge but increased the applicability of the MuSKIE model to lakes across northern Wisconsin. Spawning site data from multiple spawning seasons likely introduced some variation but should increase the reliability of the model's predictions across years (Tuanmu et al. 2011). The MuSKIE model provides a refinement in scale from whole-lake classifications of habitat factors influencing recruitment success (Dombeck et al. 1986; Rust et al. 2002) to within-lake predictions of spawning site locations.

The interpretation of AUC values is highly dependent on the species' selectivity and on the proportion of available spawning habitat that is utilized. Therefore, $\mathrm{AUC}_{\text {test }}$ and AUCtrain values should be considered in the context of the maximum attainable AUC (Phillips et al. 2006). The random placement of points representing available spawning habitat means that some proportion of the available spawning habitat $(\alpha)$ was utilized. For example, if we assume that the utilized spawning habitat is the shallow area within $125 \mathrm{~m}$ of confirmed spawning sites, then $27 \%$ of the available spawning habitat for this analysis was actually utilized for spawning. The AUC scores reflect correctly classified presence and true absence points, so the available spawning habitat data used by MaxEnt decreased the AUC score. The maximum attainable AUC (0.866) is calculated as $1-\alpha / 2$ (Phillips et al. 2006), so $\mathrm{AUC}_{\text {test }}(0.637)$ and $\mathrm{AUC}_{\text {train }}$ (0.741) should be evaluated against that value. In this context, the AUC values represent the generalist spawning selection displayed by Muskellunge for multiple habitat types among widely different lakes (Lobo et al. 2008).

The difference between $\mathrm{AUC}_{\text {train }}$ and $\mathrm{AUC}_{\text {test }}$ is likely explained by an increase in false positives for a model trained with pooled data and tested at the individual-lake scale; such a result may be due to differences in spawning habitat selection among lakes, spawning habitat availability within lakes, or the number of Muskellunge observed in each lake. Variance in individual lakes' test AUC scores increased when the number of spawning sites was low, indicating a potential decrease in performance when the density of observed spawning Muskellunge was low. Additionally, the available spawning habitat in lakes with few spawning sites or with low-density Muskellunge populations may have been poor, contributing to lower predictability in spawning site selection.

We made important assumptions in characterizing Muskellunge spawning habitat. We assumed that the observed location of a Muskellunge represented a spawning site, and we confirmed those spawning sites based on the presence of one or more Muskellunge eggs. We used the location of adult 
Muskellunge sighting as opposed to the located egg(s) because we wanted to remain consistent with the Rust et al. (2002) study and because egg transport was inferred based upon the finding of Muskellunge eggs at the water's edge. We did not attempt to quantify egg movement, but we assumed that the scale of any movement relative to our egg search radius $(100 \mathrm{~m})$ was small enough to avoid influencing verification. Observations from Horsehead Lake over repeated nights demonstrated some consistency in spotlighting data, whereas egg movement data were not quantified. Thus, for the representation of spawning sites, we placed greater confidence in spotlighting locations than in the locations of found eggs. Spatial measurement error also exists in the form of interpretation and interpolation of GIS data. However, we assumed that these geographic errors were relatively small in comparison with the distance over which Muskellunge were observed to spawn (>140 m).

The availability of reliable and relevant data potentially limited the MuSKIE model's performance. Although bathymetry data (WDNR 1939-1978) were generally corroborated by field observations, our vegetation mapping corresponded poorly with the most recent comprehensive maps of aquatic vegetation (WDNR 1939-1978). We considered these vegetation maps too dated to be trustworthy, as distributions may have shifted due to natural changes or vegetation management. During model evaluation, we found that the inclusion of vegetation and substrate maps slightly improved the model results for the subset of lakes that we mapped. However, this improvement was small, so we placed greater confidence in models tested across the full set of 28 lakes than in models tested for the 11lake subset, and we built a model that could be applied with existing data. In the future, efforts that employ remote sensing or other methods to precisely map each species of aquatic macrophyte and the fine-scale distribution of substrates would likely improve the power and applicability of such models.

The MuSKIE model identified potential Muskellunge spawning habitat in northern Wisconsin lakes. Fielding and Bell (1997) described the difficulty with modeling habitat usage by species in competition, noting that the presence of competitors in a given region will influence the habitats utilized. Competition for spawning habitat between Muskellunge and Northern Pike has been speculated (Strand 1986). Inclusion of a variable representing Northern Pike presence/absence did not improve model performance and thus failed to support this hypothesis. If such competition did exist, training the model using lakes with Northern Pike present (16 lakes) and absent (12 lakes) ensured that if Muskellunge spawning site selection differed in the presence of Northern Pike, these habitats were also included in the model.

\section{Management Application}

While degradation or loss of Muskellunge spawning habitat has been implicated in declining natural reproduction
(Dombeck et al. 1986), locating and protecting the spawning habitat in individual lakes have been limited by the time required for surveys. The MuSKIE model provides an efficient method for management agencies and conservation groups to remotely designate areas that are likely spawning habitat, thereby facilitating spawning habitat conservation. Because the model was trained and tested on lakes with different habitats and different Muskellunge densities, it should be used as an index of the relative probability of occurrence within lakes but not for comparisons of habitat quality between lakes or as the true probability of occurrence (Yackulic et al. 2013). Another model has been developed to predict the likelihood of successful reproduction by Muskellunge in a lake based on the degree of shoreline development (Rust et al. 2002). Our model output provides a relative index of spawning likelihood at a given location, upon which users can base conservation decisions. The model is based on coarse geomorphological habitat features, whereas habitat management often focuses on microhabitats. The MuSKIE model could be used to identify areas for conserving natural shorelines, restoring large woody debris, or protecting rushes; it could also be used to protect spawning Muskellunge from potential disturbances. The visual nature of the MuSKIE model's output provides a tool with which the locations and significance of spawning habitat can be communicated to the public.

Managers can identify likely Muskellunge spawning habitat in lakes with high proportions of good or poor habitat by classifying the best available habitat rated by the MuSKIE model. When the relative probability of spawning designated as an acceptable cutoff between spawning habitat presence and absence is increased, a decreasing proportion of the lake will be classified as spawning habitat. For example, if the best $40 \%$ of a lake's available habitat is selected, it should contain of $64 \%$ of the spawning sites. Similarly, if the best $20 \%$ of available habitat is selected, it should contain $32 \%$ of the spawning sites.

The MuSKIE model produced 5- $\times 5$-m grids, each of which was assigned a relative likelihood for spawning. Managers could use this information to design habitat protection plans for areas that are large enough to support spawning by Muskellunge (e.g., within $140 \mathrm{~m}$ ). If model results are used to protect areas within $140 \mathrm{~m}$ of predicted spawning sites, then a much larger proportion of spawning sites will be protected, as this strategy moves toward the protection of entire spawning grounds as opposed to individual spawning sites.

The MuSKIE model identifies where Muskellunge spawning sites likely exist, but it does not quantify how much spawning habitat is required for self-sustaining Muskellunge populations. We discussed arbitrary thresholds above, whereas managers may choose to implement any biologically significant threshold. To implement the model, managers must determine the proportion of spawning sites that must be protected in order to meet management goals. Based on the AUC information presented here, managers 
can then determine the proportion of available spawning habitat that requires protection.

\section{ACKNOWLEDGMENTS}

This study was funded by the WDNR, the Musky Clubs Alliance of Wisconsin, the University of Michigan, and the Alvan Macauley Fellowship. Many people and organizations participated in this study, and we thank them for their support and dedication. We thank J. Breck, D. Crane, and our anonymous reviewers for their suggestions on the manuscript. R. Haase and many volunteers from Musky Clubs Alliance of Wisconsin, T. Aepelbacher, K. Battige, J. Bies, L. Ettema, C. Higley, A. Layman, S. Lewandoski, D. Oele, D. Rudy, J. Schultz, and S. Upton assisted with field work. P. Cunningham, T. Simonson, and S. Bolssen (WDNR) aided in study design, logistics, and field work.

\section{REFERENCES}

Allan, J. D. 1995. Stream ecology: structure and function of running waters. Springer Press, Dordrecht, The Netherlands.

Baker, M. E., M. J. Wiley, M. L. Carlson, and P. W. Seelbach. 2003. A GIS model of subsurface water potential for aquatic resource inventory, assessment, and environmental management. Environmental Management 32:706-719.

Balon, E. K. 1975. Reproductive guilds of fishes: a proposal and definition. Journal of the Fisheries Research Board of Canada 32:821-864.

Bean, T. H. 1908. The muskalonge [sic] of the Ohio basin. Transactions of the American Fisheries Society 37:145-151.

Bozek, M. A., T. M. Burri, and R. V. Frie. 1999. Diets of Muskellunge in northern Wisconsin lakes. North American Journal of Fisheries Management 19:258-270.

Chambers, P. A. 1987. Nearshore occurrence of submersed aquatic macrophytes in relation to wave action. Canadian Journal of Fisheries and Aquatic Sciences 44:1666-1669.

Christensen, D. L., B. R. Herwig, D. E. Schindler, and S. R. Carpenter. 1996. Impacts of lakeshore residential development on coarse woody debris in north temperate lakes. Ecological Applications 6:1143-1149.

Craig, R. E., and R. M. Black. 1986. Nursery habitat of Muskellunge in southern Georgian Bay, Lake Huron, Canada. Pages 79-86 in G. E. Hall, editor. Managing muskies. American Fisheries Society, Special Publication 15, Bethesda, Maryland.

Crane, D. P., J. M. Farrell, and K. L. Kapuscinski. 2014. Identifying important micro-habitat characteristics of Muskellunge spawning locations in the upper Niagara River. Journal of Great Lakes Research 40:325-335.

Crossman, E. J. 1990. Reproductive homing in Muskellunge, Esox masquinongy. Canadian Journal of Fisheries and Aquatic Sciences 47:1803-1812.

Cummins, K. W. 1962. An evaluation of some techniques for the collection and analysis of benthic samples with special emphasis on lotic waters. American Midland Naturalist 67:477-504.

Deleo, J. M. 1993. Receiver operating characteristic laboratory (ROCLAB): software for developing decision strategies that account for uncertainty. Pages 318-25 in B. M. Ayyub, editor. Proceedings of the second international symposium on uncertainty modelling and analysis. Institute of Electrical and Electronics Engineers Press, College Park, Maryland.

Dombeck, M. P. 1979. Movement and behavior of the Muskellunge determined by radio-telemetry. Wisconsin Department of Natural Resources Technical Bulletin 113.
Dombeck, M. P., B. W. Menzel, and P. N. Hinz. 1984. Muskellunge spawning habitat and reproductive success. Transactions of the American Fisheries Society 113:205-216.

Dombeck, M. P., B. W. Menzel, and P. N. Hinz. 1986. Natural Muskellunge reproduction in Midwestern lakes. Pages 122-134 in G. E. Hall, editor. Managing muskies. American Fisheries Society, Special Publication 15, Bethesda, Maryland.

Elith, J., C. H. Graham, and National Center for Ecological Analysis and Synthesis Species Distribution Modelling Group. 2006. Novel methods improve prediction of species' distributions from occurrence data. Ecography 29:129-151.

Elith, J., S. J. Phillips, T. Hastie, M. Dudík, Y. E. Chee, and C. J. Yates. 2011. A statistical explanation of MaxEnt for ecologists. Diversity and Distributions 17:43-57.

Farmer, B., and P. Chow-Fraser. 2004. A conceptual model of Muskellunge spawning habitat. Undergraduate thesis. McMaster University, Hamilton, Ontario.

Farrell, J. M. 2001. Reproductive success of sympatric Northern Pike and Muskellunge in an upper St. Lawrence River bay. Transactions of the American Fisheries Society 130:796-808.

Farrell, J. M., R. G. Werner, S. R. LaPan, and K. A. Claypoole. 1996. Egg distribution and spawning habitat of Northern Pike and Muskellunge in a St. Lawrence River marsh, New York. Transactions of the American Fisheries Society 125:127-131.

Fielding, A. H., and J. F. Bell. 1997. A review of methods for the assessment of prediction errors in conservation presence/absence models. Environmental Conservation 24:38-49.

Fry, J., G. Xian, S. Jin, J. Dewitz, C. Homer, L. Yang, C. Barnes, N. Herold, and J. Wickham. 2011. Completion of the 2006 National Land Cover Database for the conterminous United States. Photogrammetric Engineering and Remote Sensing 77:858-864.

Geiger, F., J. Bengtsson, F. Berendse, W. Weisser, M. Emmersond, M. Morales, P. Ceryngier, J. Liirah, T. Tscharntke, C. Winqvist, S. Eggers, R. Bommarco, T. Pãrt, V. Bretagnolle, M. Plantegenest, L. Clement, C. Dennisd, C. Palmerd, J. Oñate, I. Guerrero, V. Hawro, T. Aavik, C. Thies, A. Flohre, S. Hänke, C. Fischer, P. Goedhart, and P. Inchaust. 2010. Persistent negative effects of pesticides on biodiversity and biological control potential on European farmland. Basic and Applied Ecology 11:97-105.

Haas, R. C. 1978. The Muskellunge in Lake St. Clair. Pages 334-359 in R. L. Kendall, editor. A symposium on selected coolwater fishes of North America. American Fisheries Society, Special Publication 11, Bethesda, Maryland.

Hernandez, P. A., C. H. Graham, L. L. Master, and D. L. Albert. 2006. The effect of sample size and species characteristics on performance of different species distribution modeling methods. Ecography 29:773-785.

Inskip, P. D. 1986. Negative associations between abundances of Muskellunge and Northern Pike: evidence and possible explanations. Pages 135-150 in G. E. Hall, editor. Managing muskies. American Fisheries Society, Special Publication 15, Bethesda, Maryland.

Ivlev, V. S. 1961. Experimental ecology of the feeding of fishes. Yale University Press, New Haven, Connecticut.

Johnson, F. H. 1961. Walleye egg survival during incubation on several types of bottom in Lake Winnibigoshish, Minnesota, and connecting waters. Transactions of the American Fisheries Society 90:312-322.

Kapuscinski, K. L., and J. M. Farrell. 2014. Habitat factors influencing fish assemblages at Muskellunge nursery sites. Journal of Great Lakes Research 40(Supplement 2):135-147.

LakeSat. 2001. Results of Wisconsin's first statewide lake clarity mapping using Landsat satellite remote sensing. University of Wisconsin, Environmental Remote Sensing Center, Madison. Available: www.LakeSat.org. (August 2012).

Lobo, J. M., A. Jiménez-Valverde, and R. Real. 2008. AUC: misleading measure of the performance of predictive distribution models. Global Ecology and Biogeography 17:145-151. 
Margenau, T. L. 1992. Survival and cost-effectiveness of stocked fall fingerling and spring yearling Muskellunge in Wisconsin. North American Journal of Fisheries Management 12:484-493.

Menz, F. C., and D. P. Wilton. 1983. An economic study of the Muskellunge fishery in New York. New York Fish and Game Journal 30:12-29.

Merow, C., M. J. Smith, and J. A. Silander Jr. 2013. A practical guide to MaxEnt for modeling species' distributions: what it does, and why inputs and settings matter. Ecography 36:1058-1069.

Miller, M. L., and B. W. Menzel. 1986. Movement, activity, and habitat use patterns of Muskellunge in west Okoboji Lake, Iowa. Pages 51-61 in G. E. Hall, editor. Managing muskies. American Fisheries Society, Special Publication 15, Bethesda, Maryland.

Miller, L. M., S. W. Mero, and J. A. Younk. 2009. The genetic legacy of stocking Muskellunge in a northern Minnesota lake. Transactions of the American Fisheries Society 138:602-615.

Monfette, R., S. Guénette, N. Dubuc, R. Fortin, and H. Fourneir. 1996. Northern Pike and Muskellunge spawning ecology and reproductive success in the lower Ottawa River. Pages 55-65 in S. J. Kerr and C. H. Olver, editors. Managing muskies in the 1990s. Ontario Ministry of Natural Resources, Southern Region Science and Technology Transfer Unit, Workshop Proceedings WP-007, Kemptville.

Murry, B. A., and J. M. Farrell. 2007. Quantification of native Muskellunge nursery habitat: influence of body size, fish community composition, and vegetation structure. Environmental Biology of Fishes 79:37-47.

Nohner, J. K. 2009. Development of a GIS model to predict Muskellunge spawning habitat in northern Wisconsin lakes. Master's thesis. University of Michigan, Ann Arbor.

NWS (National Weather Service) and NCDC (National Climatic Data Center). 2009. Wind Rose data: 1973-2004. NWS and NCDC, Green Bay, Wisconsin.

Oehmcke, A. A., L. Johnson, J. Klingbiel, and W. Wistrom. 1958. The Wisconsin Muskellunge: its life history, ecology, and management. Wisconsin Conservation Department, Publication 225, Madison.

Phillips, S. J., R. P. Anderson, and R. E. Schapire. 2006. Maximum entropy modeling of species geographic distributions. Ecological Modelling 190:231-259.

Phillips, S. J., and M. Dudík. 2008. Modeling species distributions with MaxEnt: new extensions and a comprehensive evaluation. Ecography 31:161-175.

Phillips, S. J., M. Dudík, and R. E. Schapire. 2008. MaxEnt software for species habitat modeling, version 3.2.19. Available: http://www.cs.princeton. edu/ schapire/maxent/.(October2008).

Pierce, R. B., J. A. Younk, and C. M. Tomcko. 2007. Expulsion of miniature radio transmitters along with eggs of Muskellunge and Northern Pike: a new method for locating critical spawning habitat. Environmental Biology of Fishes 79:99-109.

Posa, M. R., and N. S. Sodhi. 2006. Effects of anthropogenic land use on forest birds and butterflies in Subic Bay, Philippines. Biological Conservation 129:256-270

Raabe, J. K., and M. A. Bozek. 2012. Quantity, structure, and habitat selection of natural spawning reefs by Walleyes in a north temperate lake: a multiscale analysis. Transactions of the American Fisheries Society 141:1097-1108.

Rohweder, J., J. T. Rogala, B. L. Johnson, D. Anderson, S. Clark, C. Ferris, and R. Kip. 2008. Application of wind fetch and wave models for habitat rehabilitation and enhancement projects. U.S. Geological Survey, Open File Report 2008-1200, Reston, Virginia.
Roseman, E., W. W. Taylor, D. B. Hayes, R. C. Haas, R. L. Knight, and K. O. Paxton. 1996. Walleye egg deposition and survival on reefs in western Lake Erie (USA). Annales Zoologici Fennici 33:341-351.

Rust, A. J., J. S. Diana, T. L. Margenau, and C. J. Edwards. 2002. Lake characteristics influencing spawning success of Muskellunge in northern Wisconsin lakes. North American Journal of Fisheries Management 22:834-841.

Scott, W. B., and E. J. Crossman. 1973. Freshwater fishes of Canada. Bulletins of the Fisheries Research Board of Canada 184.

Smith, J. M. 1991. Wind-wave generation on restricted fetches. U.S. Army Corps of Engineers, Waterways Experiment Station, Coastal Engineering Research Center, Miscellaneous Paper 91-2, Vicksburg, Mississippi.

Strand, R. F. 1986. Identification of principal spawning areas and seasonal distribution and movements of Muskellunge in Leech Lake, Minnesota. Pages 62-73 in G. E. Hall, editor. Managing muskies. American Fisheries Society, Special Publication 15, Bethesda, Maryland.

Tuanmu, M. N., A. Viña, G. J. Roloff, W. Liu, Z. Ouyang, H. Zhang, and J. Liu. 2011. Temporal transferability of wildlife habitat models: implications for habitat monitoring. Journal of Biogeography 38:1510-1523.

WDNR (Wisconsin Department of Natural Resources). 1939-1978. Lake survey map series, 28 maps. WDNR, Madison.

WDNR (Wisconsin Department of Natural Resources). 2007. Wisconsin open water from 1:24,000-scale sources. WDNR, Madison.

WDNR (Wisconsin Department of Natural Resources). 2009. Wisconsin Department of Natural Resources and Wisconsin aquatic gap mapping application. WDNR, Madison. Available: http://infotrek.er.usgs.gov/ wdnrfish/.(April2009).

Werner, R. G., R. Klindt, and B. Jonckheere. 1996. Vegetative characteristics of Muskellunge (Esox masquinongy) spawning and nursery habitat in the Thousand Islands section of the St. Lawrence River. Great Lakes Research Review 2:29-35.

Westers, H., and R. R. Stickney. 1993. Northern Pike and Muskellunge. Pages 199-213 in R. R. Stickney, editor. Culture of nonsalmonid freshwater fishes, 2nd edition. CRC Press, Ann Arbor, Michigan.

Wetzel, R. G. 2001. Limnology, 3rd edition. Academic Press, San Diego, California.

Yackulic, C. B., R. Chandler, E. F. Zipkin, J. A. Royle, J. D. Nichols, E. H. Campbell Grant, and S. Veran. 2013. Presence-only modelling using MaxEnt: when can we trust the inferences? Methods in Ecology and Evolution 4:236-243.

Yost, A. C., S. L. Peterson, M. Gregg, and R. Miller. 2008. Predictive modeling and mapping sage grouse (Centrocercus urophasianus) nesting habitat using maximum entropy and a long-term dataset from southern Oregon. Ecological Informatics 3:375-386.

Younk, J. A., and M. F. Cook. 1992. Applications of an angler diary for Muskellunge Esox masquinongy. Minnesota Department of Natural Resources, Investigational Report 420, St. Paul.

Younk, J. A., M. F. Cook, T. J. Goeman, and P. D. Spencer. 1996. Seasonal habitat use and movements of Muskellunge in the Mississippi River. Minnesota Department of Natural Resources, Investigational Report 449, St. Paul.

Zar, J. H. 1999. Biostatistical analysis. Prentice-Hall, New York.

Zorn, S. L., T. L. Margenau, J. S. Diana, and C. J. Edwards. 1998. The influence of spawning habitat on natural reproduction of Muskellunge in Wisconsin. Transactions of the American Fisheries Society 127:995-1005. 